\section{Is the genetic variability of elite rice in southern Brazil really disappearing?}

\author{
Carlos Busanello ${ }^{1^{*}}$, Eduardo Venske ${ }^{1}$, Cássia Fernanda Stafen ${ }^{1}$, \\ Ana Marina Pedrolo ${ }^{1}$, Viviane Kopp da Luz ${ }^{1}$, Tatiana Pedron ${ }^{2}$, \\ Fernanda Pollo Paniz ${ }^{2}$, Bruno Lemos Batista ${ }^{2}$, Ariano Martins \\ de Magalhães Júnior ${ }^{3}$, Antonio Costa de Oliveira ${ }^{1}$ and Camila \\ Pegoraro $^{1}$
}

\begin{abstract}
There is a worldwide concern about a possible narrowing of the genetic base of most crops, as e.g. that of rice (Oryza sativa L.), as a result of the modern breeding practices. Thus, the purpose of this study was to investigate this phenomenon in the germplasm of elite paddy rice in southern Brazil, including frequently used accessions in crosses. The panel consisted of 91 accessions. Data of morphological traits, SNP markers and mineral content of husked and polished grain were analyzed by hierarchical clustering and principal component analysis. The SNP markers and hierarchical clustering proved most appropriate to assess the genetic variability. A narrowing of the genetic base of rice was confirmed, although a certain level of genetic variability was still found in the germplasm of elite paddy rice in south Brazilian rice, particularly for grain mineral content.
\end{abstract}

Keywords: Genetic resources, genetic variability, genotyping, phenotyping, Oryza sativa $L$.

\section{INTRODUCTION}

Rice (Oryza sativa L.) is one of the most important crops worldwide, including in Brazil, and is the primary food source of more than half of the world population, contributing to global wealth and food security (Zhang et al. 2011). In view of the importance of this crop, new improved cultivars have to be constantly developed in breeding programs, which is only possible as long as genetic variability with novel genes and alleles that control traits of economic importance are available.

From the 1960s onwards, the developing countries invested in the green revolution to supply their food demand, which resulted in high yielding cultivars, especially for wheat and rice. The intense use of these genotypes on farms as well as in breeding programs has raised the food production in these countries but has also caused losses with regard to the genetic variability (genetic erosion) (Govindaraj et al. 2015). In fact, the genetic progress in rice breeding has declined steadily over the last decades in several countries, due to the narrow genetic base of the accessions used for crosses (Aljumaili et al. 2018), even though some variability is still available within the rice gene pool. However, this diagnosis of the genetic variability has to be established for each specific germplasm, e.g., for South Brazilian paddy rice, mainly because the southern region produces
Crop Breeding and Applied Biotechnology 20(2): e262620214, 2020 Brazilian Society of Plant Breeding. Printed in Brazil http://dx.doi.org/10.1590/198470332020v20n2a30

\section{*Corresponding author: E-mail: carlosbuzza@gmail.com (D) ORCID: 0000-0001-5069-2525}

Received: 12 March 2019 Accepted: 16 August 2019 Published: 15 June 2020

${ }^{1}$ Universidade Federal de Pelotas, Faculdade de Agronomia Eliseu Maciel, Departamento de Fitotecnia, Campus Capão do Leão, 96.010-610, Pelotas, RS, Brazil

${ }^{2}$ Universidade Federal do ABC, Centro de Ciências Naturais e Humanas, Campus Santo André, 09.210-580, Santo André, SP, Brazil

${ }^{3}$ Empresa Brasileira de Pesquisa Agropecuária, Centro de Pesquisa Agropecuária de Clima Temperado, Estação Experimental Terras Baixas, 96.001-970, Pelotas, RS, Brazil 
more than $80 \%$ of all Brazilian rice (SOSBAI 2018). In fact, studies have reported evidence for the gradual narrowing of the genetic variability among the elite cultivars grown in southern Brazil (Rangel et al. 1996, Raimondi et al. 2014, Rabelo et al. 2015, Streck et al. 2018, Streck et al. 2019). However, it is important to emphasize that these studies may have applied datasets and methods with somehow restricted efficiency to evaluate the genetic variability.

Studies on genetic variability can improve the efficient use and conservation of genetic resources (Aljumaili et al. 2018). Genetic variability has been frequently measured based mainly on morphological traits. However, this approach has some disadvantages in terms of time, space, cost and labor requirements. Furthermore, it cannot define the precise level of genetic variability among accessions due to the additive gene action for trait expression and the environmental effect on the phenotypic performance. Genetic variability can also be assessed by analyzing the grain mineral content (Roy and Sharma 2014). However, this is also a phenotype-based approach, with possibly the same limitations as for morphological traits.

An alternative to the phenotypic traits are molecular markers, by which an organism can be directly characterized based on DNA features (Aljumaili et al. 2018). Molecular markers were developed in the 1980s and with the rapid increase of information regarding plant genomes, a revolution in molecular genetics has taken place, which provided a tremendous opportunity to investigate genetic variability contained in any given germplasm. These markers were successfully applied to determine and classify the genetic variability, among which the SNP (single-nucleotide polymorphism) markers are currently preferred, in view of their advantages (Nadeem et al. 2018).

Based on the above, this study investigated whether the genetic variability among rice accessions cultivated in southern Brazil and accessions used in crosses in breeding programs based on genotypic and phenotypic approaches is really becoming exhausted.

\section{MATERIAL AND METHODS}

\section{Rice panel}

A panel consisting of 91 rice accessions was selected for this study, to sample the genetic variability of the elite South Brazilian rice germplasm, including foreign cultivars widely used in crosses (Table 1). These are accessions of Brazilian cultivars released in the last four decades, introduced cultivars, a few traditional varieties and mutant lines, and one hybrid. Twenty-five conventional genotypes (i.e. not
Table 1. List of rice accessions evaluated for morphological traits, grain mineral content and SNP genotyping to determine genetic variability by different methods

\begin{tabular}{|c|c|c|c|c|c|}
\hline Code & Accession & Origin & Code & Accession & Origin \\
\hline 1 & Amarelo B & Brazil & 47 & IAS 12-9 Formosa & Brazil \\
\hline 2 & Amaroo & Australia & 48 & IRAT 124 & Brazil \\
\hline 3 & Arborio & Italy & 49 & IRAT 162 & Brazil \\
\hline 4 & Austral & Unknown & 50 & IRGA 417 & Brazil \\
\hline 5 & Basmat 370 & Pakistan & 51 & IRGA 418 & Brazil \\
\hline 6 & Brilhante & Chile & 52 & IRGA 419 & Brazil \\
\hline 7 & BR IRGA 409 & Brazil & 53 & IRGA 420 & Brazil \\
\hline 8 & BR IRGA 410 & Brazil & 54 & IRGA $424 \mathrm{CL}$ & Brazil \\
\hline 9 & BR IRGA 411 & Brazil & 55 & IRGA 427 & Brazil \\
\hline 10 & BR IRGA 412 & Brazil & 56 & IRGA 428 & Brazil \\
\hline 11 & BR IRGA 413 & Brazil & 57 & IRGA 429 & Brazil \\
\hline 12 & BR IRGA 414 & Brazil & 58 & Japonês de Várzea & Brazil \\
\hline 13 & BRS 358 & Brazil & 59 & Jasmine & Thailand \\
\hline 14 & BRS 6 Chui & Brazil & 60 & Jasmine 85 & Thailand \\
\hline 15 & BRS 7 Taim & Brazil & 61 & Koshihikari & Japan \\
\hline 16 & BRS A701 CL & Brazil & 62 & Lemont & USA \\
\hline 17 & BRS AG & Brazil & 63 & M1150 & Brazil \\
\hline 18 & BRS Agrisul & Brazil & 64 & M1313 & Brazil \\
\hline 19 & BRS Atalanta & Brazil & 65 & M1410 & Brazil \\
\hline 20 & BRS Bojuru & & 66 & Meio Chumbinho & Brazil \\
\hline 21 & BRS Cirad 302 & Brazil & 67 & MNA PB 0405 & Brazil \\
\hline 22 & BRS Firmeza & Brazil & 68 & Nowrin Mochi & Japan \\
\hline 23 & BRS Formoso & Brazil & 69 & OR 63-252 & Brazil \\
\hline 24 & BRS Fronteira & Brazil & 70 & Puita Inta CL & Argentina \\
\hline 25 & BRS Ligeirinho & Brazil & 71 & Qualimax & Brazil \\
\hline 26 & BRS Pampa & Brazil & 72 & Rexoro & USA \\
\hline 27 & BRS Pampeira & Brazil & 73 & Sambuc & France \\
\hline 28 & BRS Pelota & Brazil & 74 & SC 173 & Brazil \\
\hline 29 & BRS Querência & Brazil & 75 & SC 460 & Brazil \\
\hline 30 & BRS Sinuelo CL & Brazil & 76 & SCS 112 & Brazil \\
\hline 31 & Cachinho & Brazil & 77 & SCS 114 AndoSan & Brazil \\
\hline 32 & Cacho Grande & Brazil & 78 & SCS $115 \mathrm{CL}$ & Brazil \\
\hline 33 & Carnaroli & Italy & 79 & SCS 116 Satoru & Brazil \\
\hline 34 & Carolina & USA & 80 & SCS $117 \mathrm{CL}$ & Brazil \\
\hline 35 & EEA 404 & Brazil & 81 & SCS 118 Marques & Brazil \\
\hline 36 & EMPASC 100 & Brazil & 82 & SCS 119 Rubi & Brazil \\
\hline 37 & EMPASC 101 & Brazil & 83 & SCS $121 \mathrm{CL}$ & Brazil \\
\hline 38 & EMPASC 102 & Brazil & 84 & SCS BRS 111 & Brazil \\
\hline 39 & EMPASC 103 & Brazil & 85 & SCS BRS Tio Taka & Brazil \\
\hline 40 & EMPASC 104 & Brazil & 86 & Selenio & Italy \\
\hline 41 & EMPASC 105 & Brazil & 87 & Soulanet & France \\
\hline 42 & EPAGRI 106 & Brazil & 88 & Tetep & Vietnam \\
\hline 43 & EPAGRI 107 & Brazil & 89 & Tomoe Mochi & Japan \\
\hline 44 & EPAGRI 108 & Brazil & 90 & TOX 514-16-101-1 & Nigeria \\
\hline 45 & EPAGRI 109 & Brazil & 91 & Zebu & Unknown \\
\hline 46 & Guri Inta CL & Argentina & & & \\
\hline
\end{tabular}

In bold: conventional cultivars currently recommended for paddy rice cultivation in southern Brazil (SOSBAI 2018). 
a special type or hybrid) from the indica sub-group currently recommended (not obsolete) for paddy rice cultivation in southern Brazil (SOSBAI 2018), hereafter called Current South Brazilian Elite (CSBE) cultivars, received special attention in this study.

\section{Field conditions for morphological and grain mineral content analysis}

For the morphological trait measurement and grain production for mineral content analysis, the panel cultivars were grown at the Experimental station Terras Baixas of Embrapa Temperate Climate, in Capão do Leão, state of Rio Grande do Sul, southern Brazil, in the 2016/2017 growing season. The experiment was arranged in a completely randomized block design, with three replications in 1.0-m single-row plots, spaced $0.2 \mathrm{~m}$ apart. All crop management practices were applied according to the recommendations for rice cultivation in southern Brazil (SOSBAI 2018).

\section{Morphological trait measurements}

Five plants per row were evaluated for the following 10 traits: number of panicles per plant, panicle weight, number of grains and sterile grains per panicle, 1000-grain weight, lemma color, sterile glume color and caryopsis length, width and thickness.

\section{Grain mineral content}

For the analysis of grain mineral content, the accessions were harvested by hand in stage R8 [phenological scale of Counce et al. (2000)] and the grains were dried. The mineral content was measured in both husked and polished (white) rice. To this end, the samples for polished rice were husked and polished for $2 \mathrm{~min}$ in a mill test (Suzuki, model S21, MT). Next, all samples were ground (MARCONI, model MA020, Piracicaba-SP). The content of 11 minerals was determined (As, $\mathrm{Ca}, \mathrm{Co}, \mathrm{Cu}, \mathrm{Cr}, \mathrm{Fe}, \mathrm{Mg}, \mathrm{Mn}, \mathrm{P}$, Se and $\mathrm{Zn}$ ). In general, the samples were prepared and analyzed as described by Paniz at al. (2018). The samples were analyzed by inductively coupled plasma mass spectrometry (ICP-MS Agilent 7900, Hachioji, Japan), at the Federal University of ABC, in Santo André, São Paulo.

\section{Genotyping with SNP markers}

The panel was genotyped with 7,098 SNP markers of the 7K Infinium SNP genotyping platform (Illumina ${ }^{\circ}$ ) at the laboratory of genotyping services of the International Rice Research Institute - IRRI / Philippines (updated version of $6 \mathrm{~K}$ Infinium array; Thomson et al. 2017). A filtering procedure was carried out using TASSEL V.5.2.41 (Bradbury et al. 2007), where SNPs with missing data $>20 \%$ and minor allele frequency $\leq 5 \%$, were removed, leaving 4,973 high quality SNPs for the analysis.

\section{Statistical analysis}

To make the results comparable, all four datasets were subjected to the same statistical analyses, i.e., distancebased map, principal component analysis and hierarchical clustering. Firstly, a genetic distance matrix was calculated, based on the Euclidean distance metric. This matrix was transformed into a cluster distance heat map, for a simple and direct visualization of the genetic distances among the accessions. For hierarchical clustering, the previously generated Euclidean distance matrix was used and the Average Linkage method was applied. A cut-off was assigned by the Mojena (1977) methodology, where the cut-off $=$ mean $+K(1.25) * S D$. For principal component analysis (PCA), the K-means algorithm was applied to cluster the genotypes and the Elbow criteria to determine the number of groups. Finally, the hierarchical group containing most accessions separated by the K-means algorithm in the four treatments were compared to verify the common and the exclusive accessions in a Venn diagram. Normalization was applied to all analyses to adjust to the scale of each variable. Software Orange v. 3.18 was used for all analyses and graphically displayed (Demsar et al. 2013).

\section{RESULTS AND DISCUSSION}

In this study, genetic variability was measured in a selected panel of rice accessions based on four distinct datasets, i.e., of morphological traits, genotyping with SNP markers and grain mineral content of husked and polished rice. Two statistical analyses were applied to each dataset, i.e., hierarchical clustering combined with genetic distance heat map 


\section{Busanello et al.}

and principal component analysis (PCA). The application of each dataset and analysis resulted in slightly distinct findings, but common features of this germplasm were also observed.

Based on the morphological traits, hierarchical clustering formed five groups, while five genotypes were not clustered in any group (Figure $1 \mathrm{~A}$ ). The major part ( $75 \%$ of the genotypes) of all accessions were grouped in one (yellowish) of the five clusters. Almost all current south Brazilian elite (CSBE) cultivars were assigned to this group, while all other types of accessions were also represented, e.g., foreign cultivars and traditional varieties. Among the accessions that

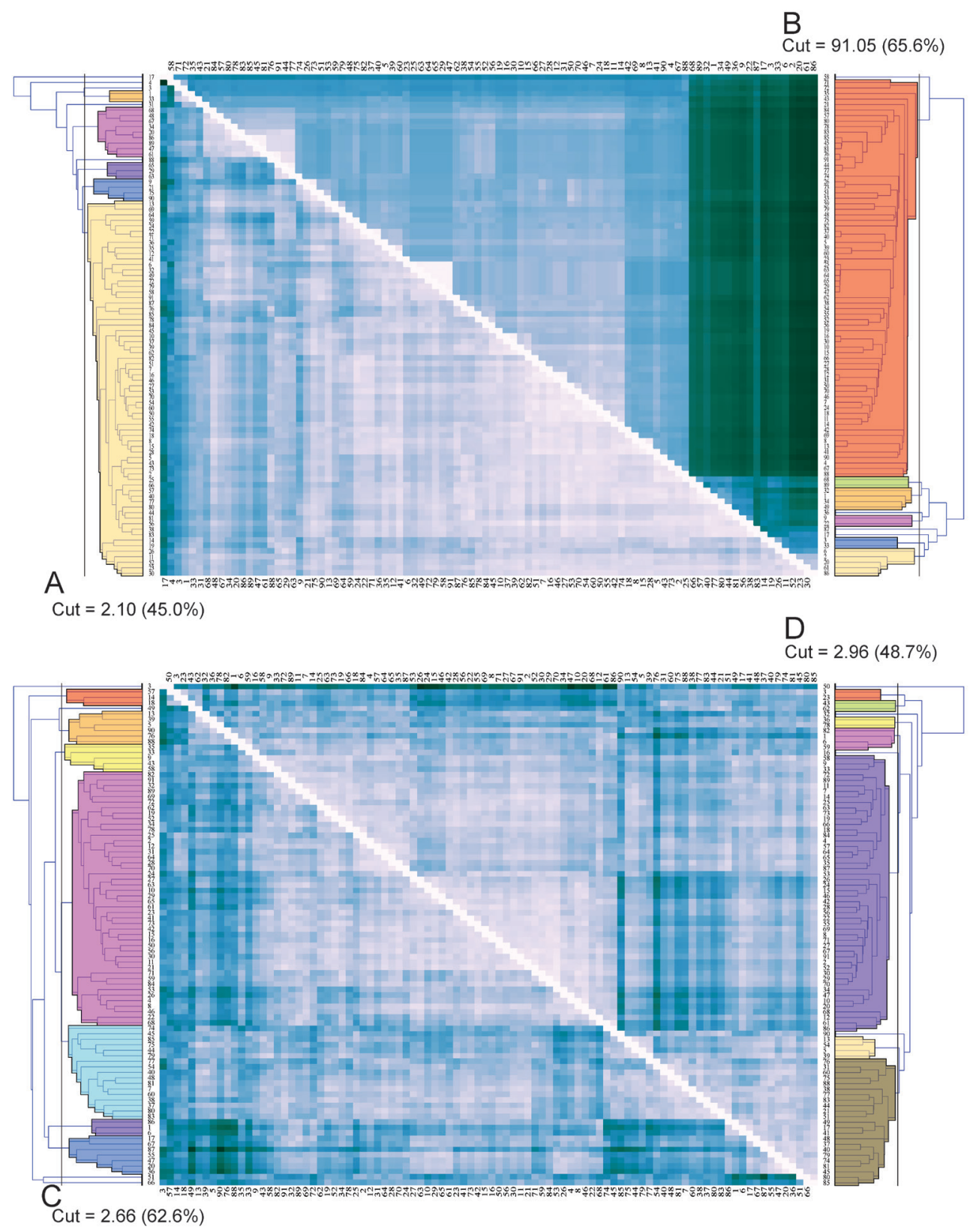

Figure 1. Euclidean distance, heat map and hierarchical clustering by average linkage method resulting from the analysis of different datasets of a panel of South Brazilian rice accessions, including genotypes frequently used to breed rice germplasm: A) morphological traits; B) genotyping with 4,973 high quality SNP markers; C) mineral content of husked rice grain; D) mineral content of polished rice grain. 
were not clustered in this main group, only BRS Querência is a representative of the CSBE cultivars. The smallest group (orange) contained only two accessions, one of which was a traditional variety and the other a foreign cultivar. A visual grouping of the genotypes by the genetic distance heat map was not possible, since the range of genetic distances was narrow (mean genetic distance $=1.64$ ). The use of morphological traits to assess genetic variability within a given germplasm is a widely applied strategy in this field of research (e.g. Cargnelutti Filho et al. 2010). Based on this approach, a recently published study, focused on the South Brazilian rice germplasm, showed that most of the genotypes were also clustered in a single large group, which allowed the conclusion of an expressive narrowing of the genetic variability of this germplasm, especially within the indica group (Streck et al. 2017, Streck et al. 2018). However, it is well known that results of studies based on phenotypic data alone may be imprecise, especially due the confounding environmental effect. Moreover, phenotypic assessments are subjected to human errors, in particular visual evaluations, which are usually also rather time-consuming.

For the SNP dataset (Figure 1B), hierarchical clustering defined six groups, and four accessions were not grouped. Similarly, as for the morphological traits, a very large cluster (red) contained most of the evaluated genotypes ( 79\%). All CSBE cultivars, with exception of cvs. BRS Firmeza and SCS BRS Tio Taka, were clustered in this largest group. However, again all other types of accessions were also found in this cluster, similarly as in the morphological trait analysis. For this dataset, the mean genetic distance was expressively high (54.22). Consequently, the genetic distance heat map allowed a clear visual separation of the clusters, confirming the hierarchical clustering. Summing up, molecular markers circumvent the environmental effect in genetic studies. Moreover, it is a technology with an impressive scope, since thousands of loci in hundreds of genotypes can now be assessed within only a few days (Rasheed et al. 2017, Nadeem et al. 2018). Another key advantage of this approach is that SNP markers established by the current technologies are well-distributed across the genome (Thomson et al. 2017), which allows inferences on the genetic variability even of traits not measured in the study, due to the linkage phenomenon. Studies using biochemical/molecular markers to assess the genetic variability of Brazilian rice are rare (Guidolin et al. 1994, Rangel et al. 1996, Malone et al. 2006, Branco et al. 2007, Raimondi et al. 2014), but also agree with this study, evidencing a certain level of narrowing of the genetic diversity of this germplasm. The scarcity of studies applying molecular markers is due to the still high cost of these technologies and the need for qualified staff to perform the analysis.

For mineral content of rice grain, the results show a less threatening scenario, as more groups were found by the hierarchical analysis and the size of these groups was smaller. Grain mineral content of husked rice formed seven groups, while four genotypes were not included in any cluster (Figure 1C). The largest group (pink) contained approximately half of the evaluated genotypes, however, only 14 of the 25 CSBE participated in this group. Although a range of visual genetic distances was calculated (mean $=1.72$ ), the groups formed by hierarchical clustering could not be confirmed by a heat map. For grain mineral content of polished rice, a total of seven groups were also formed, and once again four accessions were not clustered in any group (Figure 1D). The largest group (purple) contained $~ 55 \%$ of the accessions. Of these 50 genotypes, 16 were CSBE cultivars. Of the remaining nine CSBE cultivars, six were clustered in the second largest group (gray). Once again, the genetic distance heat map could not distinguish the groups formed by hierarchical clustering (mean genetic distance $=1.86$ ). In southern Brazil, mineral content of rice grain has not been a main target of breeding programs, but rather yield potential along with grain quality (industrial and cooking properties), followed by other field traits, such as adaptation to variable environments, earliness, tolerance to abiotic and resistance to biotic stresses, among others (Streck et al. 2018). In other words, virtually no direct selection for enhanced grain mineral storage has been applied to the studied germplasm. This explains why the clustering obtained with this dataset did not fully agree with the one based on morphological traits and even on molecular markers. The detected variability can be attributed to the origin of the genotypes (Pinson et al. 2015) and also to unintentional selection, as studies have found evidence that selection for improved yield may also change the grain content of several elements (Anandan et al. 2011). In fact, studies of worldwide panels found high genetic variability for rice mineral content (Anandan et al. 2011, Pinson et al. 2015), i.e., any future lack of genetic variability can be improved by the exploitation of foreign accessions.

Across all datasets, a key result, especially of the analysis of morphological traits and SNP datasets, was the frequent clustering of most CSBE cultivars in a single group. When interpreting clustering analysis, evidence for a relatively narrow genetic variability within a group of evaluated genotypes is either the formation of few groups, but more importantly, the clustering of most genotypes in a single large group. This aspect was well-documented in this study, mainly for the 


\section{Busanello et al.}

analysis of morphological traits and SNP markers by hierarchical clustering.

A surprising lack of the well-known phenomenon "breeder signature" (Ali et al. 2011, Xie et al. 2015) was observed in all datasets, since several cultivars developed in different breeding programs (Embrapa Temperate Climate, Irga, Basf, Epagri) and even foreign genotypes clustered together. Possible reasons are that these programs develop cultivars with similar breeding targets, i.e. mainly yield potential, for a similar geographical region and mainly for paddy rice cultivation.

Similar evidence was described by Reig-Valiente et al. (2016), who showed that breeding for a specific region even tends to genetically isolate the germplasm regarding adaptability. The second reason is probably more important, as studies have named the causes for the narrowing of the genetic base of rice by genealogy records, showing that few ancestors represent the base of practically all breeding programs, and that in addition, over decades, few parents were used repeatedly in crosses, affecting the resulting variability (Rangel et al. 1996, Raimondi et al. 2014, Rabelo et al. 2015).
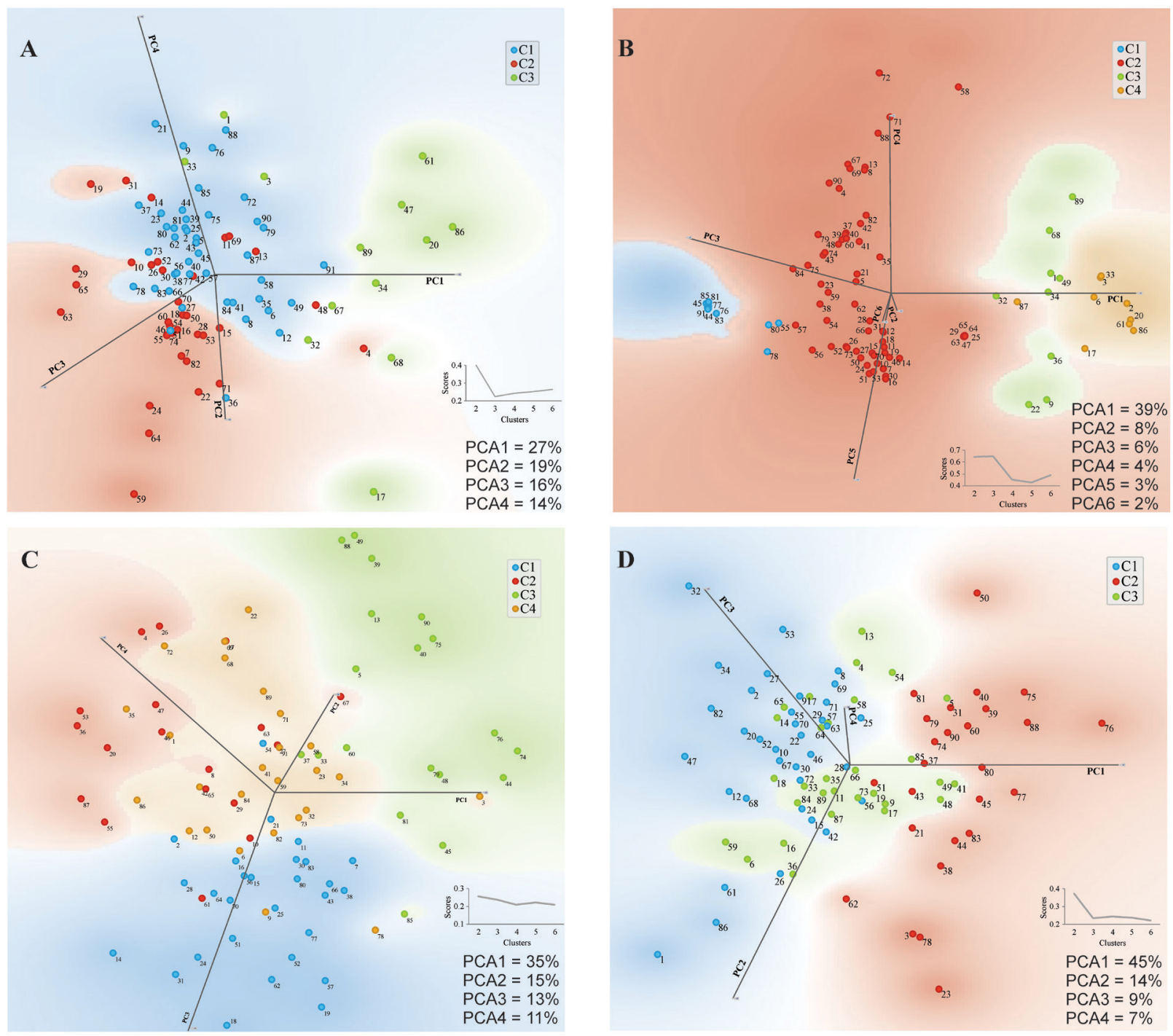

Figure 2. Principal component analysis based on different datasets of a panel of South Brazilian rice accessions, including genotypes frequently used to breed this germplasm: A) morphological traits; B) genotyping of 4,973 high quality SNP markers; C) mineral content of husked rice grain; D) mineral content of polished rice grain. On the right side of Figures A-D, the number of components needed to explain a reasonable amount of genetic variability in the analysis and a K-means plot that indicates the optimal number of clusters resulting from the analysis of each dataset. 
Regarding the datasets used in this study, it is possible to assume that the results of SNP markers are the most refined. An important evidence in this sense is the high mean genetic distance (54.22) for this dataset (versus morphological data 1.64; mineral content of husked rice 1.72; mineral content of polished grain 1.86). Molecular markers are not only stable in the genome of the evaluated plants, but are also unaffected by trait expression and independent from interactions with other genomic sequences. In agreement of the importance identify SNPs associated with a desirable trait, is their application in genome-wide association studies, which have been applied in rice accessions for agronomic important traits (Changrog et al., 2020). On the other hand, any phenotypic dataset is a result of not only environmental effects but also of influences of specific genetic and genomic architectures, in which several phenomena, such as gene expression, can affect the types of gene mode and even epigenetic controls.

To confirm the results of the hierarchical method, a PCA analysis was carried out and groups were formed, using the same datasets (Figure 2). Based on the morphological trait dataset (Figure 2A), four components explained $76 \%$ of the genetic variation and the applied method suggested three groups of genotypes. The largest group (blue) comprised $\sim 47 \%$ of the accessions, the second group (red) $\sim 38 \%$ and the smallest (yellow) only $\sim 14 \%$ of the genotypes. The largest group contained 10 and the second largest cluster 15 CSBE accessions. The smallest group consisted basically of foreign japonica cultivars and traditional varieties. The PCA analysis of the SNP dataset required six components to explain $62 \%$ of the genetic variability of the measured panel (Figure 2B). Four clusters were generated, of which the largest (red) comprised $\sim 69 \%$ of the accessions, and 19 CSBE. The second largest group (blue) contained $\sim 12 \%$ of the accessions and six CSBE cultivars.

In the PCA analysis for mineral content of husked rice, four components explained $74 \%$ of the genetic variation and four groups were established (Figure $2 \mathrm{C}$ ). The largest group (blue) contained $31 \%$ of the genotypes and 11 CSBE cultivars. Finally, in the PCA analysis of mineral content of polished rice, four components explained $75 \%$ of the genetic variation and three clusters were formed (Figure 2D). Approximately 38\% (blue), 29\% (red) and 33\% (yellow) of the genotypes were grouped per clusters. Surprisingly, CSBE cultivars were evenly distributed across all three groups, as also found for the traditional varieties and foreign genotypes. Importantly, for both datasets of husked and polished grain mineral content, there was no clear clustering of cultivars according to the breeding company that developed the cultivars. Once more, this indicates the presence of genetic variability within the measured panel for these traits.

Venn diagrams were constructed to elucidate the agreement between groupings (Figure 3). For hierarchical clustering, a total of 25 accessions in common were present in the largest group resulting from each dataset, of which 12 are CSBE cultivars (Figure $3 A$ ). Regarding PCA, only two accessions in common were grouped in the largest cluster of each dataset (BRS Ligeirinho and IRGA 428, a CSBE cultivar) (Figure $3 B$ ).

A comparison of the clustering methods showed that hierarchical clustering allowed the formation of more groups than the PCA analysis, for all datasets. It has been clearly demonstrated that different clustering analysis

A

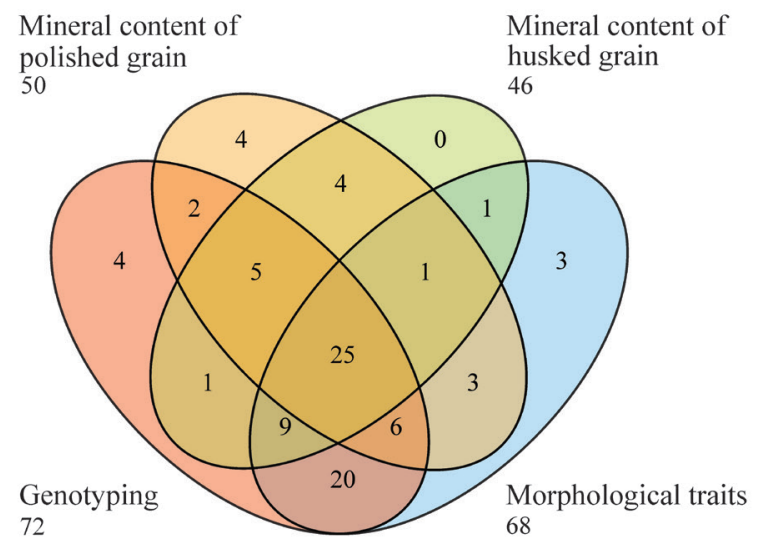

B Morphological traits 43

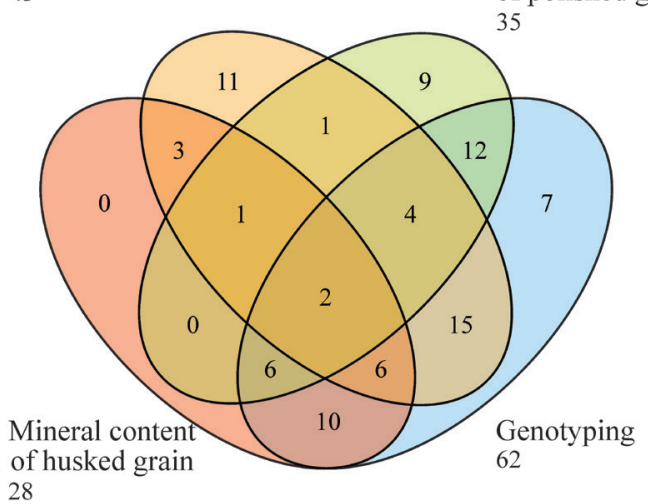

Figure 3. Venn diagram. The number of accessions clustered in the largest group resulting from each analysis is plotted to illustrate the overlapping groups. A) Hierarchical clustering; B) Principal component analysis. 


\section{Busanello et al.}

methods may result in distinct findings (Cargnelutti Filho et al. 2010). A classical requirement for a proper interpretation of PCA analysis is that few components should explain a large amount of variation in a dataset, usually of $>80 \%$. In this study, the first components of none of the PCA analysis explained $>76 \%$ of the variation, and adding more components improved this result only minimally. Thus, taking this point into consideration, it is possible to suggest that hierarchical clustering is more reliable for this dataset.

In crop breeding programs, the analysis of the genetic variability of the germplasm under study is of paramount importance, as this variability is simply the raw material, the basis, on which selection can be successfully carried out. There is a worldwide concern that the genetic variability of most crops will gradually become eroded, due to the current practices of breeding programs, in which few parents are used for crosses and a high selection pressure is applied to a very limited range of phenotypes, also called the funnel effect (Wouw et al. 2009). For bread wheat (Triticum aestivum L.), a crop with a naturally narrow genetic variability, this threat has been widely recognized among researchers (Reif et al. 2005). Although the rice gene pool is considerably richer in comparison with wheat, there are indications of a narrowing of the genetic variability of the crop, especially in the elite germplasm, which has been under selection. The international literature has described this phenomenon (Aljumaili et al. 2018), but important reports on a narrowing of the Brazilian rice germplasm have also been published (Rangel et al. 1996, Raimondi et al. 2014, Rabelo et al. 2015, Streck et al. 2018, Streck et al. 2019).

Generally, it was found that a certain level of variability for immediate use in South Brazilian rice breeding programs is still available, especially for breeding for grain mineral content, but also for morphological and other traits, as indicated by SNP analysis. Thus, genotypes of one given cluster can be a source of variability for accessions of another. This result was somehow confirmed by a recent study that showed a linear increase in the genetic progress of South Brazilian rice over the last 45 years (Streck et al. 2018). However, the prevalent result of this study indicated a concerning situation of erosion of the genetic variability of Brazilian rice, which will probably impair the genetic progress of the crop within a few years. Furthermore, the genetic vulnerability caused by this narrow variability also has to be taken into account, with regard to the threat of biotic epidemics and even abiotic factors triggered by the ongoing climate change (Raimondi et al. 2014). Breeders and researchers have to be concerned and respond with the application of strategies to broaden the genetic variability of Brazilian paddy rice, be it by mutagenesis, by gene introgression from wild relatives and landraces or even by biotechnological approaches, such as the cutting-edge technology of genome editing.

\section{CONCLUSIONS}

For the evaluated germplasm, SNP markers and hierarchical clustering are the most appropriate tools to assess genetic variability. The narrowing of the genetic base of rice mentioned in the literature was confirmed here. Nevertheless, a certain level of genetic variability within the germplasm of South Brazilian elite paddy rice is still available, especially for grain mineral content.

\section{REFERENCES}

Ali ML, McClung AM, Jia MH, Kimball JA, McCouch SR and Georgia CE (2011) A rice diversity panel evaluated for genetic and agromorphological diversity between subpopulations and its geographic distribution. Crop Science 51: 2021-2035.

Aljumaili SJ, Rafii MY, Latif MA, Sakimin SZ, Arolu IW and Miah G (2018) Genetic diversity of aromatic rice germplasm revealed by SSR markers. BioMed Research International 2018: 1-11.

Anandan A, Rajiv G, Eswaran R and Prakash M (2011) Genotypic variation and relationships between quality traits and trace elements in traditional and improved rice (Oryza sativa L.) genotypes. Journal of Food Science 76: H122-H130.

Bradbury PJ, Zhang Z, Kroon DE, Casstevens TM, Ramdoss Y and Buckler ES (2007) TASSEL: software for association mapping of complex traits in diverse samples. Bioinformatics 23: 2633-2635.

Branco JSC, Vieira EA, Malone G, Kopp MM, Malone E, Bernardes A, Mistura CC, Carvalho FIF and Oliveira AC (2007) IRAP and REMAP assessments of genetic similarity in rice. Journal of Applied Genetics 48: 107-113.

Cargnelutti Filho A, Ribeiro ND and Burin C (2010) Consistência do padrão de agrupamento de cultivares de feijão conforme medidas de dissimilaridade e métodos de agrupamento. Pesquisa Agropecuária Brasileira 45: 236-243.

Changrong $Y$, Hengming L, Wei D, Jinwen Z, Yuran X, Anyu G, Yonggang L, Wei N, Shengli S, Hua A, Ying L, Lihua Z, Xuebao Y, Ju L, Gunagde L, Zhenghe L, Wei P, Dinghong Z and Xiaolin L (2020) Genome-wide association study on agronomic traits of temperate japonica rice (Oryza sativa L.). Crop Breeding and Applied Biotechnology 20: e22462011. 
Is the genetic variability of elite rice in southern Brazil really disappearing?

Counce PA, Keisling TC and Mitchell AJ (2000) A uniform, objective, and adaptive system for expressing rice development. Crop Science 40: 436-443.

Demsar J, Curk T, Erjavec A, Gorup C, Hocevar T, Milutinovic M, Mozina M, Polajnar M, Toplak M, Stari A, Stajdohar M, Umek L, Zagar L, Zbontar J, Zitnik M and Zupan B (2013) Orange: data mining toolbox in Python. The Journal of Machine Learning Research 14: 2349-2353.

Govindaraj M, Vetriventhan M and Srinivasan M (2015) Importance of genetic diversity assessment in crop plants and its recent advances: an overview of its analytical perspectives. Genetics Research International 2015: 1-14.

Guidolin AF, Oliveira AD, Terres A and Costa FCD (1994) Caracterização eletroforética das cultivares de arroz irrigado em uso no RS. Lavoura Arrozeira 47: 3-5.

Malone G, Zimmer PD, Kopp MM, Mattos LAT, Carvalho FIF and Oliveira AC (2006) Assessment of the genetic variability among rice cultivars revealed by amplified fragment length polymorphism (AFLP). Current Agricultural Science and Technology 12: 21-25.

Mojena R (1977) Hierarchical grouping methods and stopping rules: an evaluation. The Computer Journal 20: 359-363.

Nadeem MA, Nawaz MA, Shahid MQ, Doğan Y, Comertpay G, Yıldız M, Hatipoğlu R, Ahmad F, Alsaleh A, Labhane N, Özkan H, Chung G and Baloch FS (2018) DNA molecular markers in plant breeding: current status and recent advancements in genomic selection and genome editing. Biotechnology \& Biotechnological Equipment 32: 261-285.

Paniz FP, Pedron T, Freire BM, Torres DP, Silva FF and Batista BL (2018) Effective procedures for the determination of $\mathrm{As}, \mathrm{Cd}, \mathrm{Cu}, \mathrm{Fe}, \mathrm{Hg}$, $\mathrm{Mg}, \mathrm{Mn}, \mathrm{Ni}, \mathrm{Pb}, \mathrm{Se}, \mathrm{Th}, \mathrm{Zn}, \mathrm{U}$ and rare earth elements in plants and foodstuffs. Analytical Methods 10: 4094-4103.

Pinson SRM, Tarpley L, Yan W, Yeater K, Lahner B, Yakubova E, Huang $X-Y$, Zhang M, Guerinot ML and Salt DE (2015) Worldwide genetic diversity for mineral element concentrations in rice grain. Crop Science 55: 294-311.

Rabelo HO, Guimarães JFR, Pinheiro JB and Silva EFD (2015) Genetic base of Brazilian irrigated rice cultivars. Crop Breeding and Applied Biotechnology 15: 146-153.

Raimondi JV, Marschalek R and Nodari RO (2014) Genetic base of paddy rice cultivars of Southern Brazil. Crop Breeding and Applied Biotechnology 14: 194-199.

Rangel PHN, Guimarães EP and Neves PCF (1996) Base genética das cultivares de arroz (Oryza sativa L.) irrigado do Brasil. Pesquisa Agropecuária Brasileira 31: 349-357.
Rasheed A, Hao Y, Xia X, Khan A, Xu Y, Varshney RK and He Z (2017) Crop breeding chips and genotyping platforms: progress, challenges, and perspectives. Molecular Plant 10: 1047-1064.

Reif JC, Zhang P, Dreisigacker S, Warburton ML, van Ginkel M, Hoisington D, Bohn M and Melchinger AE (2005) Wheat genetic diversity trends during domestication and breeding. Theoretical and Applied Genetics 110: 859-864.

Reig-Valiente JL, Viruel J, Sales E, Marqués L, Terol J, Gut M and Domingo C (2016) Genetic diversity and population structure of rice varieties cultivated in temperate regions. Rice 9: 58.

Roy SC and Sharma DB (2014) Assessment of genetic diversity in rice [Oryza sativa L.] germplasm based on agro-morphology traits and zinc-iron content for crop improvement. Physiology and Molecular Biology of Plants 20: 209-224.

SOSBAI - Sociedade Sul-Brasileira de Arroz Irrigado (2018) Arroz irrigado: Recomendações técnicas da pesquisa para o sul do Brasil, Farroupilha, RS. Sociedade Sul-Brasileira de Arroz Irrigado, Cachoeirinha, 205p.

Streck EA, Magalhães Júnior AM, Aguiar GA, Facchinello PHK and Fagundes PRR (2019) Genotypic performance, adaptability and stability in special types of irrigated rice using mixed models. Revista Ciência Agronômica 50: 66-75.

Streck EA, Magalhães Júnior AM, Aguiar GA, Facchinello PHK, Fagundes PRR, Franco DF, Nardino M and Oliveira AC (2018) Genetic progress in 45 years of irrigated rice breeding in southern Brazil. Crop Science 58: 1094-1105.

Thomson MJ, Singh N, Dwiyanti MS, Wang DR, Wright MH, Perez FA, DeClerck G, Chin JH, Malitic-Layaoen GA, Juanillas VM, Dilla-Ermita CJ, Mauleon R, Kretzschmar T and McCouch SR (2017) Large-scale deployment of a rice $6 \mathrm{~K} \mathrm{SNP}$ array for genetics and breeding applications. Rice 10: 40.

Wouw M van de, Kik C, Hintum, T van, Treuren R van and Visser B (2009) Genetic erosion in crops: concept, research, results and challenges. Plant Genetic Resources 8: 1-15.

Xie W, Wang G, Yuan M, Yao W, Lyu K, Zhao H, Yang M, Li P, Zhang X, Yuan J, Wang Q, Liu F, Dong H, Zhang L, Li X, Meng X, Zhang W, Xiong L, He Y, Wang S, Yu S, Xu C, Luo J, Li X, Xiao J, Lian X and Zhang Q (2015) Breeding signatures of rice improvement revealed by a genomic variation map from a large germplasm collection. Proceedings of the National Academy of Sciences 112: E5411-E5419.

Zhang P, Li J, Li X, Liu X, Zhao X and Lu Y (2011) Population structure and genetic diversity in a rice core collection (Oryza sativa L.) investigated with SSR markers. PLoS ONE 6: e27565. 